\title{
Press hardening of alternative materials: conventional high-
}

\section{strength steels}

\author{
Joseba Mendiguren ${ }^{1 a^{*}}$, Nuria Herrero-Dorca $^{1 \mathrm{~b}}$, Eneko Saenz de Argandoña ${ }^{1 \mathrm{c}}$, \\ Lander Galdos ${ }^{1 \mathrm{~d}}$
}

${ }^{1}$ Dept. of Mechanical and Industrial Production, Mondragon Unibertsitatea, Loramendi 4,

Mondragon 20500, Gipuzkoa, Spain

jimendiguren@mondragon.edu, ${ }^{\mathrm{b}}$ nherrero@mondragon.edu, ${ }^{\mathrm{c}}$ esaenzdeargan@mondragon.edu, ${ }^{\mathrm{d}}$

Igaldos@mondragon.edu

*Corresponding author

Keywords: press hardening, hot stamping, formability, high-strength steel

\section{Abstract}

The increase in strength of new high strength steels (HHS) and advanced high strength steels (AHHS) has led to forming issues, such as high springback, low formability, increase of forming forces and tool wear. These problems increase the costs of manufacturing and maintaining stamping tools in the automotive industry. The aim of this research was to analyse the advantages of applying the press- hardening process to conventional HSS and AHSS steel to increase their formability and therefore reduce the number of forming steps and production costs. With this aim in mind, the press-hardening process was used to manufacture an industrial component using four different automotive steel grades: dual phase (DP), complex phase (CP), transformationinduced plasticity (TRIP) and martensitic (MS) grade. Springback measurements were carried out, together with an analysis of the obtained final mechanical properties and microstructures. The results showed that the formability of all the materials increased. The mechanical properties of the CP800 and TRIP700 materials were maintained or even improved, whereas those of the MS1200 and HCT980X materials were significantly reduced. We conclude that press hardening is a suitable manufacturing process for CP800 and TRIP700 components. 


\section{Introduction}

Weight reductions in the body of a car has been the main driver of new car design development in the last decade. Such reductions are necessary if European and international CO2 emission targets are to be achieved. To reach the required reductions, new materials have been introduced in the structure of the car. These include the use of new metals and composites or hybrid metal/composite materials. Due to their high price, the former are currently only used in high-class or luxury models. Different metallic materials (e.g. steel, aluminium and magnesium) are also being incorporated in the body of cars to improve their performance (i.e. reduce their weight). Magnesium, as the lightest metal $\left(1740 \mathrm{~kg} / \mathrm{m}^{3}\right)$, is the most attractive material in terms of weight reduction. Some lightweight alloys, such as AZ31 or ZM21, are available [1], but their poor formability and manufacturing difficulties have relegated them to use only in specific products [2]. Aluminium alloys $\left(2800 \mathrm{~kg} / \mathrm{m}^{3}\right)$ are currently used for inner panels (5xxx and 6xxx families) and outer skin panels (6xxx family), and some extruded aluminium is incorporated on the chassis [3]. However, the amount of aluminium used in the body in white of the car is limited [4], as the strength/weight ratio is inferior to that of highstrength steel (HSS), AHSS and UHSS [5].

Steel makers have increased the performance of steel, producing steel with strengths of up to $1400 \mathrm{MPa}$ (MS1400 steel) and $1000 \mathrm{MPa}$ (DP1000 steel). However, this increase in the strength of the material comes with two main drawbacks: high springback and poor formability [6]. The high levels of stress reached during forming lead to high elastic recovery during die opening. This phenomenon, together with the complex behaviour of these multi-phase steels (i.e. nonlinear elastic behaviour) [7] and strong Bauschinger effect [8], makes the prediction of the final shape and therefore the optimal tool design a critical task in the manufacturing process. A clear example of the scope of the problem can be seen by a search of the Compendex and Inspector databases, with more than 1000 research papers published on the topic in the last 5 years. The complex microstructural characteristics of high-strength materials result in a poor formable structure, which usually causes manufacturing problems [9]. The elongation capacity of conventional steel is around $40 \%$, whereas that of DP1000 and MS1200 materials is $10 \%$ and 4\%, respectively. This difference in elongation capacity has major consequences for stamping process design of HSS components [10].

In recent years, the press-hardening process has come to the fore as an alternative to overcome the problem of high springback and poor formability [11]. In this process, the sheet is first heated to $950^{\circ} \mathrm{C}$ to produce a 
fully austenitic microstructure. Next, the forming is undertaken while the material is in an austenitic structure, thereby reducing the forming forces and increasing the formability. Finally, the dies are kept closed for around 8-10 s to force rapid quenching of the sheet material reaching a final fully martensitic microstructure, with a strength of around $1500 \mathrm{MPa}$. This process not only increases the formability but also reduces the springback because the deformation occurs at high temperature [12]. The base material used in this process is $22 \mathrm{MnB5}$, which is specially designed to allow full quenching during the process [13].

The main objective of the present study was to analyse the advantages of applying the press-hardening process to conventional HSS and AHSS steel to increase their formability and therefore reduce the number of forming steps and production costs. With this aim in mind, using the press-hardening process, an industrial component was manufactured from four different automotive steel grades, with different microstructure configurations: dual phase (DP), complex phase (CP), transformation-induced plasticity (TRIP) and martensitic (MS) grade. In addition to measuring the springback, the mechanical properties and microstructure of the resultant materials were investigated. Finally, some conclusions were drawn about the capabilities of these materials when using the press-hardening process.

\section{Materials}

To include a wide range of automotive grades, four different materials were studied: TRIP700, CP800, DP HCT980X and MS1200. Table 1 shows the characteristic mechanical properties of the four materials, with TRIP700 the softest and MS1200 the strongest.

Table 1. Thickness and mechanical properties of the analysed materials.

\begin{tabular}{cccc}
\hline Material & Thickness & Re (MPa) & Rm (MPa) \\
\hline TRIP700 & $1.5 \mathrm{~mm}$ & 520 & 740 \\
CP800 & $1.35 \mathrm{~mm}$ & 680 & 800 \\
HCT980X & $1.5 \mathrm{~mm}$ & 910 & 1060 \\
MS1200 & $1.5 \mathrm{~mm}$ & 1180 & 1340 \\
\hline
\end{tabular}




\section{Manufacturing process}

As described in Section 1 (Introduction), the press-hardening process was carried out in four successive steps:

a) Heating of the blank to the austenitization temperature

b) Transfer of the blank from the furnace to the press

c) Drawing while the blank was at a high temperature and the dies were cold

d) Quenching of the component on the closed dies

Figure 1 shows the final shape of the formed component and the handling system of the blank from the furnace to the press. The component is about $1 \mathrm{~m}$ in length.

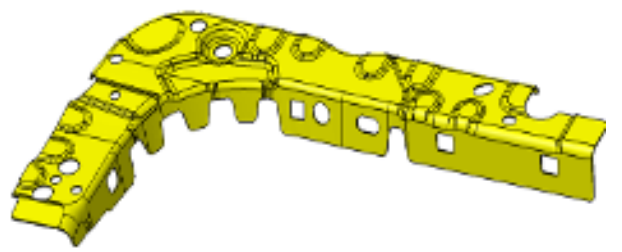

(a)

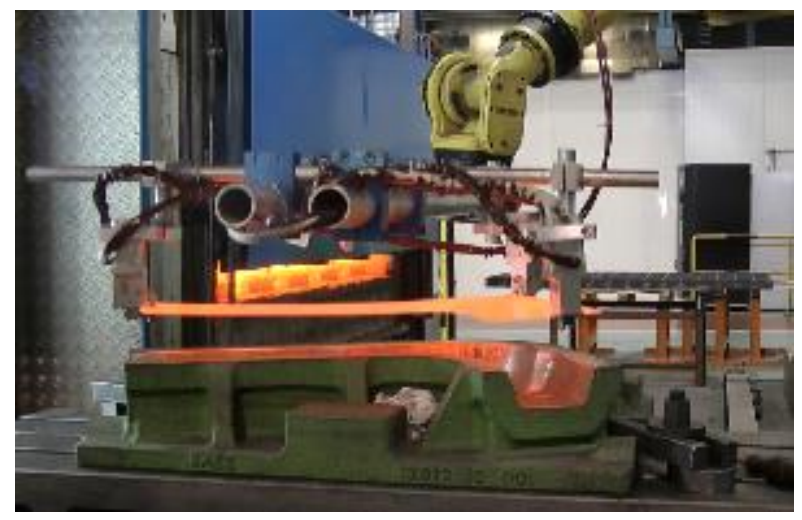

(b)

Fig. 1 Hot stamping process. a) Formed geometry and b) testing facilities

The formed component (Fig. 1a) had a main flanging operation, with some small drawing/embossing on the top. As shown in Figure 1b, the experiment was carried out in an industrial press-hardening facility, equipped with a robot feeder.

To analyse the effect of the austenitization of the blank on the process, two different methodologies were analysed (Table 2 ). In the first case (Process 1 ), the blank was heated to $700^{\circ} \mathrm{C}$, which is below the theoretical critical eutectoid temperature. In the second case (Process 2 ), the blank was heated to $950^{\circ} \mathrm{C}$, assuring complete austenitization of the material. In both cases, the heating time (time that the blank was maintained in the furnace for austenitization) and closure time (time that the dies were kept closed after forming for the quenching) were $300 \mathrm{~s}$ and $10 \mathrm{~s}$, respectively. The room temperature (cold stamping) process was studied, as the forming tool was built to support hot-stamping forces, which are much lower than those of cold-forming 
ones. No lubricant or cooling system was used in these tests. However, the temperature of the tool was controlled before each trial and was $35^{\circ} \mathrm{C}$ in each case.

Table 2. Hot stamping trial of the forming process conditions.

\begin{tabular}{llll}
\hline Forming process & Furnace temperature & Heating time & Closure time \\
\hline Process 1 & $700^{\circ} \mathrm{C}$ & $300 \mathrm{~s}$ & $10 \mathrm{~s}$ \\
Process 2 & $950^{\circ} \mathrm{C}$ & $300 \mathrm{~s}$ & $10 \mathrm{~s}$ \\
\hline
\end{tabular}

\section{Results}

Using the methodology described in Section 3, four materials were formed. Other than reducing the forming forces, the main objective was to reduce the springback. Thus, during the press-hardening process, the material was subjected to high-temperature changes to modify its microstructure and therefore its mechanical behaviour, and the dimensional accuracy of the formed component was analysed.

\subsection{Dimensional accuracy}

Eighteen points were measured to determine the shape of the formed component compared to the ideal shape (Fig. 1a). These measurements are shown in Figure 2, with differences above $0.5 \mathrm{~mm}$ highlighted in red and those below $0.5 \mathrm{~mm}$ of deviation highlighted in green.

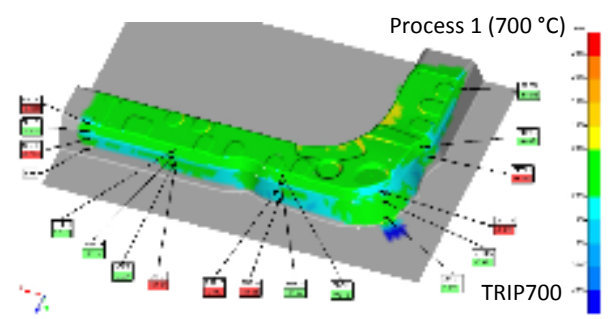

(a)

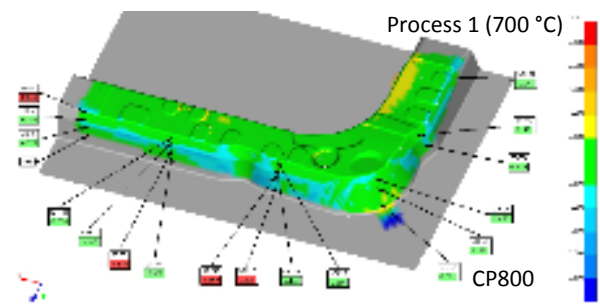

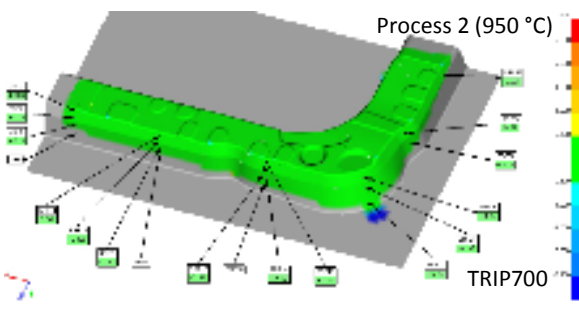

(b)

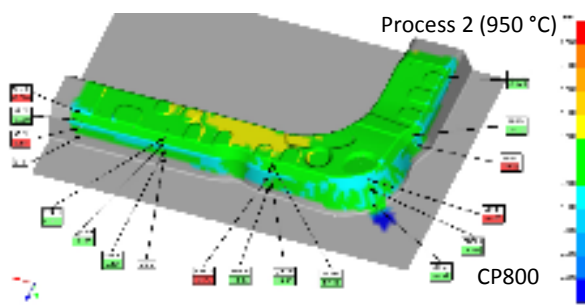


(c)

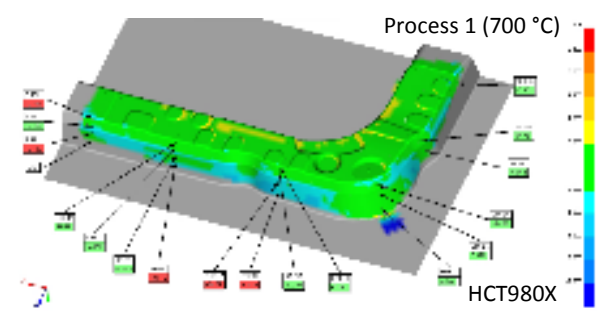

(e)

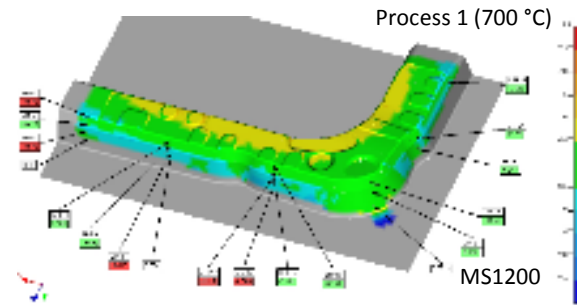

(g) (d)

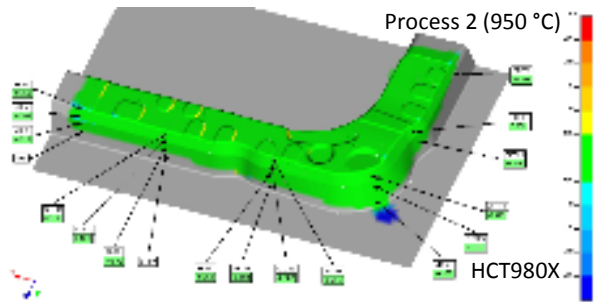

(f)

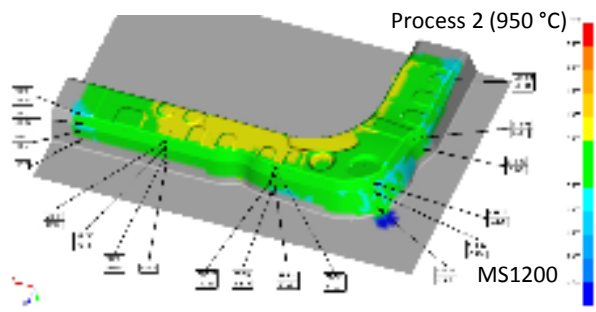

(h)

Fig. 2 Dimensional accuracy by photogrammetry, showing the four materials and both processes

From the measurement points, the average absolute deviation (abs. deviation average) and maximum absolute deviation (max. deviation value) were calculated and are represented in Table 3.

Table 3. Averaged values of the dimensional deviation, with nominal geometry.

\begin{tabular}{|c|c|c|c|}
\hline Material & Process & Abs. deviation average & Max. deviation value \\
\hline & Process $1\left(700^{\circ} \mathrm{C}\right)$ & $0.23 \mathrm{~mm}$ & $0.66 \mathrm{~mm}$ \\
\hline & Process $2\left(950^{\circ} \mathrm{C}\right)$ & $0.09 \mathrm{~mm}$ & $0.34 \mathrm{~mm}$ \\
\hline & Process $1\left(700^{\circ} \mathrm{C}\right)$ & $0.26 \mathrm{~mm}$ & $1.05 \mathrm{~mm}$ \\
\hline & Process $2\left(950^{\circ} \mathrm{C}\right)$ & $0.22 \mathrm{~mm}$ & $0.60 \mathrm{~mm}$ \\
\hline & Process $1\left(700^{\circ} \mathrm{C}\right)$ & $0.22 \mathrm{~mm}$ & $0.77 \mathrm{~mm}$ \\
\hline & Process $2\left(950^{\circ} \mathrm{C}\right)$ & $0.15 \mathrm{~mm}$ & $0.45 \mathrm{~mm}$ \\
\hline & Process $1\left(700^{\circ} \mathrm{C}\right)$ & $0.33 \mathrm{~mm}$ & $0.90 \mathrm{~mm}$ \\
\hline & Process $2\left(950^{\circ} \mathrm{C}\right)$ & $0.26 \mathrm{~mm}$ & $0.71 \mathrm{~mm}$ \\
\hline
\end{tabular}


As shown in Table 3, increasing the temperature from $700^{\circ} \mathrm{C}$ to $950^{\circ} \mathrm{C}$ reduced the springback effect. In all cases, both the average deviation and the maximum deviation were significantly reduced. The fact that the tool (Fig. 1b) was designed for $1.5 \mathrm{~mm}$-thick materials could explain why the CP800 (1.35 mm-thick) material showed less reduction than the others.

During heating in Process $2\left(950^{\circ} \mathrm{C}\right)$, the surface integrity of CP800, TRIP700 and MS1200 was degraded, with the coating becoming detached from the surface. In contrast, the surface integrity of DP HCT980X remained intact.

\subsection{Post-process mechanical properties}

As mentioned in Section 1 (Introduction), temperature changes during the forming process induce changes in a material's microstructure and therefore in its mechanical properties. To evaluate the final mechanical properties after Process 1 and Process 2, tensile samples were cut from the post-formed component, as shown in Figure 3.

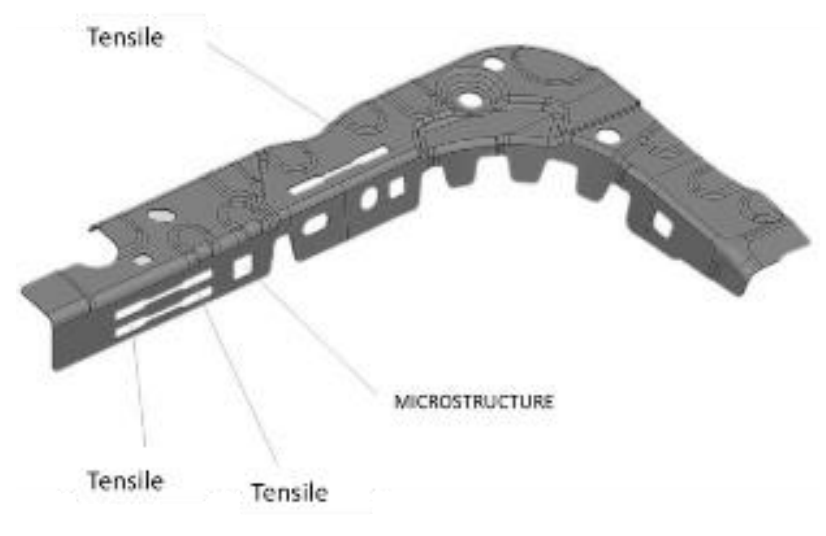

Fig. 3 Post-forming mechanical property measurement

Tensile tests of the cut samples were conducted, according to the ASTM-E8 standard. The results were then compared with those of the as-received material. The results of the comparison are shown in Figure 4. In this figure, the behaviour of the as-received material is represented in a continuous line, the after-Process 1 behaviour is represented by the dashed line, and the after-Process 2 behaviour is represented by the dash-dot line. 


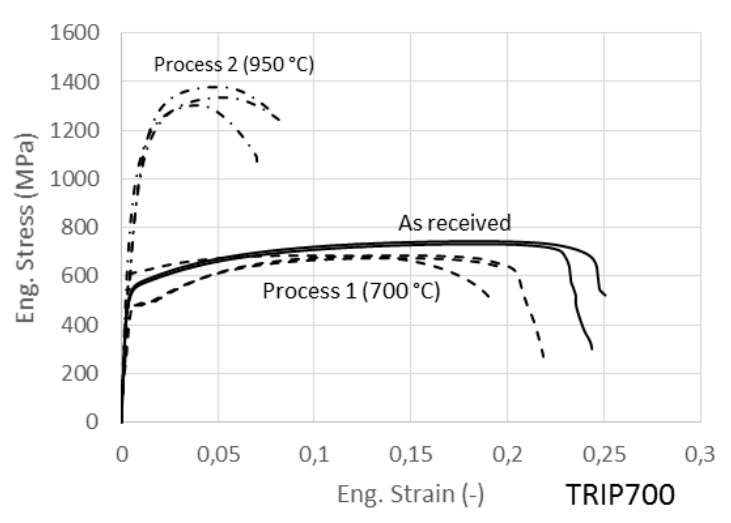

(a)

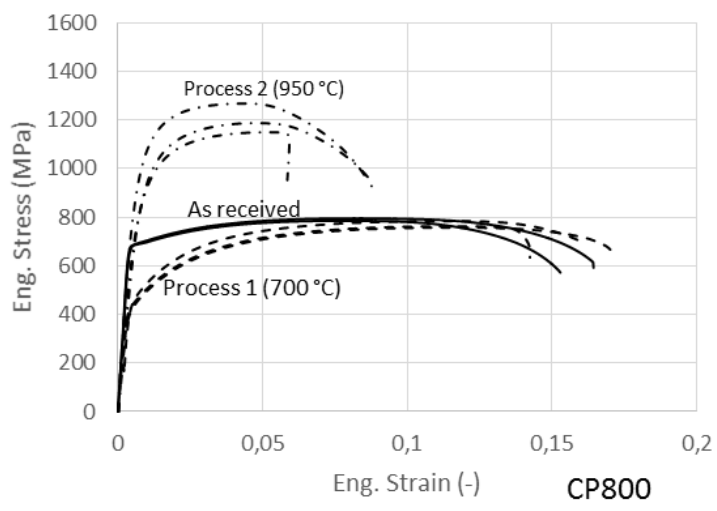

(b)

Fig. 4 Post-forming mechanical properties. a) TRIP700, b) CP800, c) HCT980X and d) MS1200. The continuous line shows the mechanical properties of the as-received material, the dashed line depicts the properties after Process $1\left(700^{\circ} \mathrm{C}\right)$, and the dot-dashed line represents the properties after Process $2\left(950^{\circ}\right.$

C)

Table 4 presents the results of the evaluation of the performance of the formed components, showing the final mechanical properties and the difference (\%) in the MPa of the as-received and treated materials.

Table 4. Differences (\%) in the final mechanical properties of the formed components.

\begin{tabular}{|c|c|c|c|c|c|c|c|}
\hline \multirow[t]{2}{*}{ Material } & \multirow{2}{*}{$\begin{array}{l}\text { Process } \\
\text { Process } 1\left(700^{\circ} \mathrm{C}\right)\end{array}$} & \multicolumn{2}{|c|}{$\operatorname{Re}(\mathrm{MPa})$} & \multicolumn{2}{|l|}{ Rm (MPa) } & \multicolumn{2}{|l|}{$A \%$} \\
\hline & & 474 & $(-8 \%)$ & 670 & $(-9 \%)$ & 20 & $(+16 \%)$ \\
\hline & Process $2\left(950^{\circ} \mathrm{C}\right)$ & 1132 & (+117 \%) & 1350 & (82\%) & 8 & $(-66 \%)$ \\
\hline & Process $1\left(700^{\circ} \mathrm{C}\right)$ & 400 & $(-41 \%)$ & 800 & $(0 \%)$ & 17 & $(+6 \%)$ \\
\hline
\end{tabular}




$\begin{array}{lcccccc}\text { Process 2 }\left(950^{\circ} \mathrm{C}\right) & 1027 & (+51 \%) & 1200 & (50 \%) & 8 & (-50 \%) \\ \text { Process } 1\left(700^{\circ} \mathrm{C}\right) & 600 & (-34 \%) & 670 & (-36 \%) & 22 & (+10 \%) \\ \text { Process } 2\left(950^{\circ} \mathrm{C}\right) & 972 & (+6 \%) & 1091 & (+3 \%) & 9 & (-55 \%) \\ \text { Process } 1\left(700^{\circ} \mathrm{C}\right) & 600 & (-49 \%) & 723 & (-46 \%) & 18 & (+260 \%) \\ \text { Process 2 }\left(950^{\circ} \mathrm{C}\right) & 750 & (-36 \%) & 960 & (-28 \%) & 9 & (+44 \%)\end{array}$

\subsection{Microstructural analysis}

Optical microscopy (OM) was used to analyse the initial microstructure of the different types of AHSS as well as the microstructural change during Process 1 and Process 2 . The OM images were taken at a magnification of 1000x. To identify all existing phases, Beraha I etching was applied to the samples. This etchant colours ferrite phases white, martensite appears black or dark brown, and bainite and tempered martensite appears light brown. The results are shown in Figures 5-8.

The initial microstructure of the TRIP700 material was complex and consisted of different, phases (ferrite, bainite, martensite and retained austenite), as shown in Figure 5a. After Process 1, the OM revealed no particular changes in the microstructure. However, after Process 2, the microstructure was modified as the temperature of $950^{\circ} \mathrm{C}$ achieved during Process 2 led to grain growth and a fully austenitic microstructure. After processing and due to high cooling rates, the resulting microstructure was martensitic, with retained austenite.

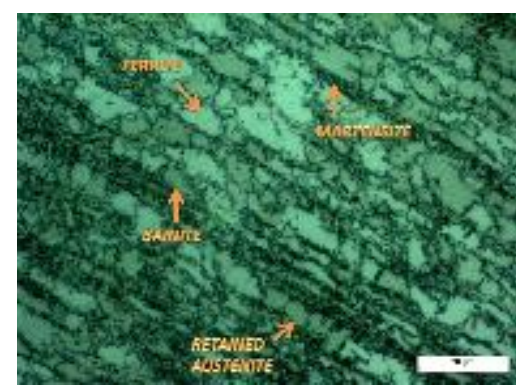

(a)

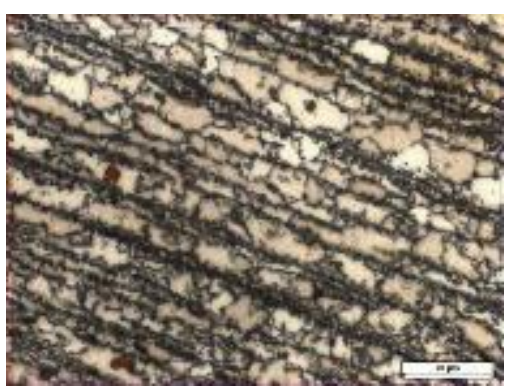

(b)

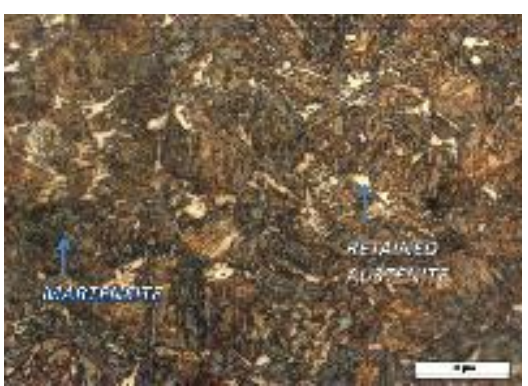

(c)

Fig. 5 Microstructure of the TRIP700 material. a) As received material, b) post-Process $1\left(700^{\circ} \mathrm{C}\right)$ and c) postProcess $2\left(950^{\circ} \mathrm{C}\right)$ 
The microstructure of CP steel is very similar to that of TRIP steel, as both materials are a combination of ferrite, bainite, martensite and retained austenite (Fig. 5a, Fig. 6a). However, CP800 contains various elements, such as $\mathrm{Nb}, \mathrm{Ti}$ and/or $\mathrm{V}$, that cause precipitation and strengthening effects, which increase its tensile yield strength [14]. In addition, CP steel contains less retained austenite and more hard phases, such as martensite and bainite, due to the alloying elements which postpone the transformation of ferrite. Due to the increase in the amount of martensite, after Process 1, some small precipitates were observed (Fig. 6b), which were probably caused by the tempering of the martensite. After Process 2, a martensitic microstructure was obtained, with retained austenite (Fig. 6c).

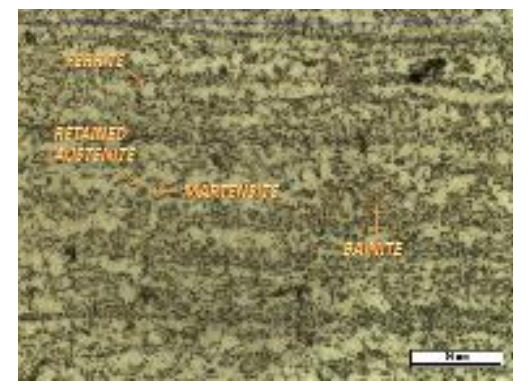

(a)

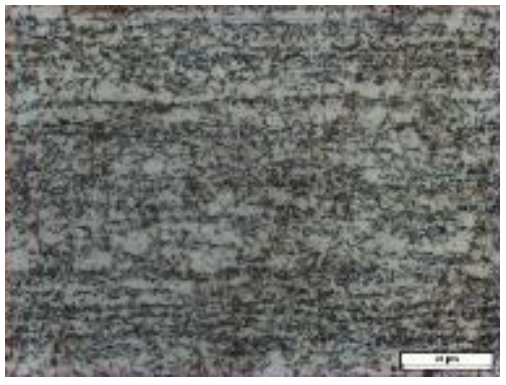

(b)

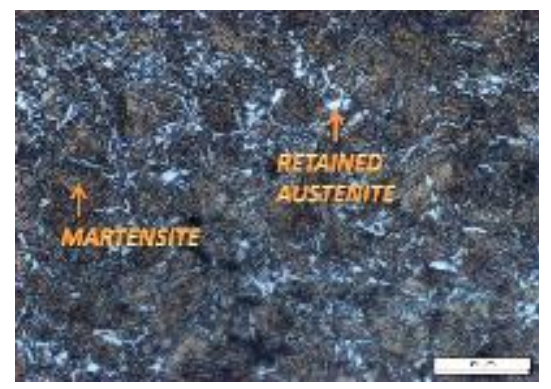

(c)

Fig. 6 Microstructure of the CP800 material. a) As received material, b) post-Process $1\left(700^{\circ} \mathrm{C}\right)$ and c) postProcess $2\left(950^{\circ} \mathrm{C}\right)$

The HCT980X alloy consists of a ferritic matrix, containing a hard martensitic second phase in the form of small islands of about $1 \mu \mathrm{m}$, as can be seen in Figure 7a. The initial structure of the MS1200 material was composed of martensite and small amounts of bainite (Fig. 8a). During Process 1, heating of both materials near to eutectoid temperature $\left(700^{\circ} \mathrm{C}\right)$ reduced the strength by tempering the martensite, which was over-tempered due to the high temperature achieved (Fig. 7b and Fig. 8b). After Process 2, the austenite was transformed, leading to a microstructure formed mainly of martensite and retained austenite (Fig. 8c). Bainite was also apparent in the microstructure of the HCT980X alloy (Fig. 7c). 


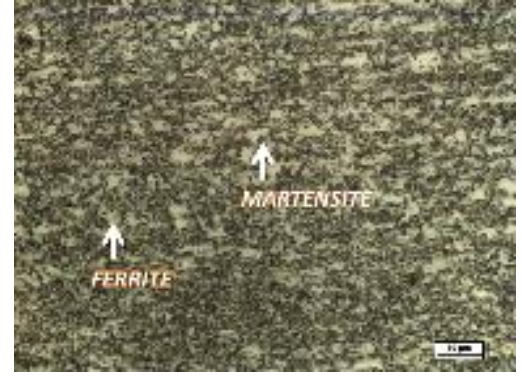

(a)

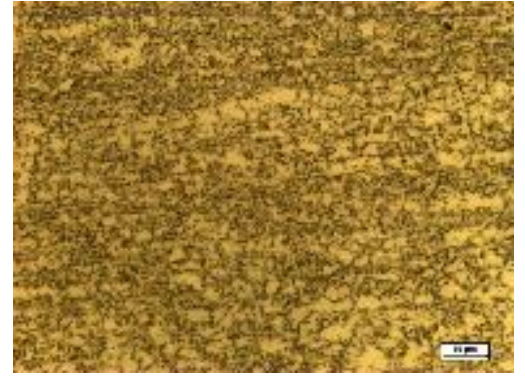

(b)

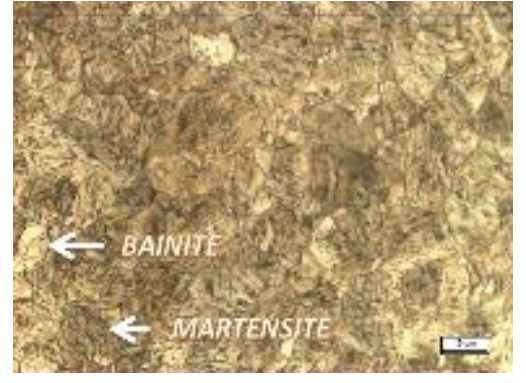

(c)

Fig. 7 Microstructure of the HCT980X material. a) As received material, b) post-Process $1\left(700^{\circ} \mathrm{C}\right)$ and c) post-Process $2\left(950^{\circ} \mathrm{C}\right)$

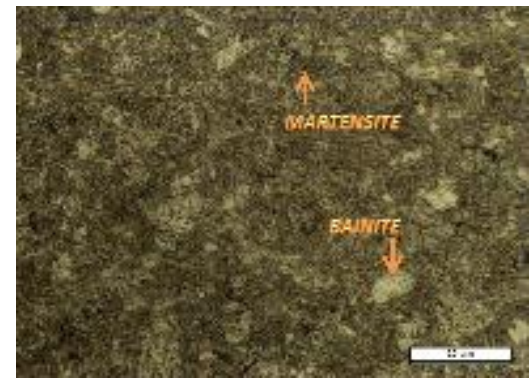

(a)

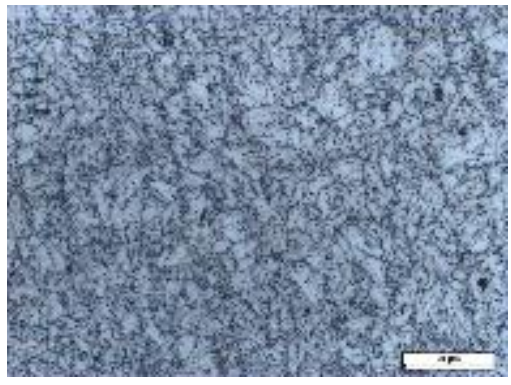

(b)

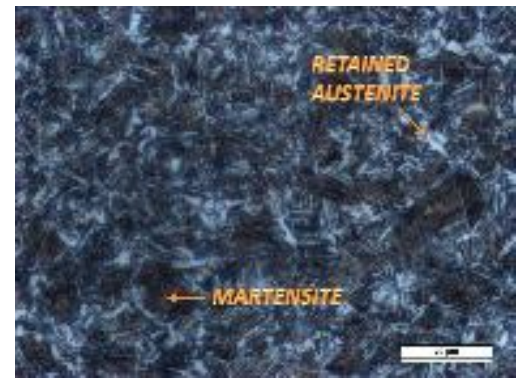

(c)

Fig. 8 Microstructure of the MS1200 material. a) As received material, b) post-Process $1\left(700^{\circ} \mathrm{C}\right)$ and c) postProcess $2\left(950^{\circ} \mathrm{C}\right)$

\section{Discussion}

The yield strengths of the four materials analysed in this work decreased after Process 1 . The decrease in TRIP700 and CP800 was not very pronounced, with heating to $700^{\circ} \mathrm{C}$ inducing only slight microstructural changes in these alloys. On the contrary, as expected, the decrease in the yield strength of HCT980X and MS1200 was much more evident. These alloys were softened after overtempering of the martensite, as both materials contained a considerable fraction of martensite in the as received state. Accordingly, elongation of both steels increased after Process 1.

After Process 2 , due to $950^{\circ} \mathrm{C}$ heating, the austenitic microstructures obtained for the four materials were transformed to almost fully martensitic microstructures. As a result, the yield strengths obtained after Process 2 were higher than those after Process 1. 
Regarding TRIP700 and CP800, the values of yield strengths obtained after Process 2 were higher than those of the as-received materials. Both materials had an initial complex multi-phase microstructure, with TRIP700 having a soft ferrite matrix, and CP800 having a ferrite/bainite matrix, embedded with hard phases. After Process 2, this soft matrix disappeared, and it was replaced with harder martensite, which was responsible for the high yield strength and reduced formability of TRIP700. Nevertheless, CP800 showed higher elongation than TRIP700, which was correlated with the higher volume of retained austenite observed in its microstructure (Fig. 5c and Fig. 6c).

In contrast, the yield strength of the HCT980X and MS1200 alloys did not increase significantly after Process 2. In the case of HCT980X, as can be seen in Figure $7 c$, the final resulting microstructure was a combination of large grains of martensite and retained austenite, and the yield strength was similar to that of the as received material, with a soft ferrite matrix and small grains of hard martensite. However, the number of soft phases and the increase in the size of the martesite grains (from $1 \mu \mathrm{m}$ in the as received material to $6 \mu \mathrm{m}$ after Process 2) reduced the elongation of the alloy from $19 \%$ to $9 \%$.

In the case of MS1200, the yield strength was lower after Process 2 than that of the as received material, although both microstructures were almost fully martensitic. The decrease in the yield strength occurred due to the increase in the size of the martensite grains after processing (Fig. 8a and Fig. 8c). Regarding elongation, the material showed better formability due to a large amount of retained austenite present in the final microstructure.

From a processing point of view, we conclude that both TRIP700 and CP800 can be subjected to Process 1 to increase their formability, without compromising their mechanical properties. These materials show interesting properties, which could be applied to tailored tempered components [15]. The final fatigue behaviour of these new microstructures remains to be tested.

\section{Conclusions}

The main objective of this work was to analyse the advantages of applying the press-hardening process to conventional HSS and AHSS steel. Based on the findings of the present study, the following conclusions can be drawn:

- An increase in temperature reduced springback deviations after forming. 
- Process $1\left(700^{\circ} \mathrm{C}\right)$ did not modify the mechanical properties of the CP800 and TRIP700 alloys, whereas Process $2\left(950^{\circ} \mathrm{C}\right)$ significantly increased the final strength while reducing the elongation of these alloys.

- Both forming processes increased the formability of the MS1200 and HCT980X materials, reducing their strength by approximately $20-30 \%$

The press-hardening process may be useful for CP800 and TRIP700 materials.

\section{Acknowledgements}

The authors acknowledge the support of their industrial partner, the automotive toolmaker, BATZ S. Coop.

\section{Compliance with Ethical Standards}

Conflict of Interest for all authors - None

\section{References}

[1] Zhou G, Ananthaeswara K, Mitukiewicz G, Li D, Mishra RK, Jain MK. FE simulations of gas blow forming and prediction of forming limit diagram of AZ31 magnesium sheet. Journal of Materials Processing Technology 2015; 218: 12-22.

[2] Ambrogio G, Filice L, Gagliardi F. Formability of lightweight alloys by hot incremental sheet forming. Materials \& Design 2012; 34: 501-508.

[3] Buffa G, Campanella D, Pellegrino S, Fratini L. Weld quality prediction in linear friction welding of AA6082T6 through an integrated numerical tool. Journal of Materials Processing Technology 2016; 231: 389-396.

[4] Zhou J, Wang F, Wan X. Optimal Design and Experimental Investigations of Aluminium Sheet for Lightweight of Car Hood. Materials Today: Proceedings 2015; 2: 5029-5036.

[5] Rehrl J, Mraczek K, Pichler A, Werner E. Mechanical properties and fracture behavior of hydrogen charged AHSS/UHSS grades at high- and low strain rate tests. Materials Science and Engineering: A 2014; 590: 360-367.

[6] Wang W, Li M, He C, Wei X, Wang D, Du H. Experimental study on high strain rate behavior of high strength 600-1000 MPa dual phase steels and 1200 MPa fully martensitic steels. Materials \& Design 2013; 47: 510-521.

[7] Mendiguren J, Cortés F, Gómez X, Galdos L. Elastic behaviour characterisation of TRIP 700 steel by means of loading-unloading tests. Materials Science and Engineering: A 2015; 634: 147-152.

[8] Tang B, Lu X, Wang Z, Zhao Z. Springback investigation of anisotropic aluminum alloy sheet with a mixed hardening rule and Barlat yield criteria in sheet metal forming. Materials \& Design 2010; 31: 2043-2050.

[9] Anderson D, Winkler S, Bardelcik A, Worswick MJ. Influence of stress triaxiality and strain rate on the failure behavior of a dual-phase DP780 steel. Materials \& Design 2014; 60: 198-207.

[10] Wu-rong W, Chang-wei H, Zhong-hua Z, Xi-cheng W. The limit drawing ratio and formability prediction of advanced high strength dual-phase steels. Materials \& Design 2011; 32: 3320-3327. 
[11] Karbasian H, Tekkaya AE. A review on hot stamping. Journal of Materials Processing Technology 2010; 210: 2103-2118.

[12] Uppaluri R, Helm D. Thermomechanical characterization of 22MnB5 steels with special emphasis on stress relaxation and creep behavior. Materials Science and Engineering: A 2016; 658: 301-308.

[13] Mendiguren J, Ortubay R, de Argandoña ES, Galdos L. Experimental characterization of the heat transfer coefficient under different close loop controlled pressures and die temperatures. Applied Thermal Engineering 2016; 99: 813-824.

[14] Bhattacharya D. Niobium Containing Advanced High Strength Steels for Automotive ApplicationsProcessing. Materials Science Forum 2014; 773-774: 325-335.

[15] Bardelcik A, Worswick MJ, Winkler S, Wells MA. A strain rate sensitive constitutive model for quenched boron steel with tailored properties. International Journal of Impact Engineering 2012; 50: 49-62. 